\title{
BMJ Open Prevalence and associated factors of self-reported ischaemic heart disease and/or stroke: a cross-sectional nationally representative community- based study of adults in Malawi in 2017
}

Supa Pengpid, ${ }^{1,2}$ Karl Peltzer (D) ${ }^{2,3}$

To cite: Pengpid S,

Peltzer K. Prevalence and associated factors of selfreported ischaemic heart disease and/or stroke: a cross-sectional nationally representative communitybased study of adults in Malawi in 2017. BMJ Open 2021;11:e048167. doi:10.1136/ bmjopen-2020-048167

- Prepublication history for this paper is available online. To view these files, please visit the journal online (http://dx.doi. org/10.1136/bmjopen-2020048167).

Received 20 December 2020 Accepted 10 September 2021

A) Check for updates

(c) Author(s) (or their employer(s)) 2021. Re-use permitted under CC BY-NC. No commercial re-use. See rights and permissions. Published by BMJ.

${ }^{1}$ ASEAN Institute for Health Development, Mahidol University, Salaya, Nakhon Pathom, Thailand

${ }^{2}$ Department of Research Administration and Development, University of Limpopo, Sovenga, Limpopo, South Africa

${ }^{3}$ Department of Psychology, Asia University, Taichung, Taiwan

Correspondence to

Dr Karl Peltzer;

kfpeltzer@gmail.com

\section{ABSTRACT}

Objective This study aimed to assess the prevalence and associated factors of self-reported ischaemic heart disease (IHD) and/or stroke among adults in Malawi. Design Population-based cross-sectional study. Setting Nationally representative sample of general adult population in Malawi.

Participants The sample included 4187 persons aged 18-69 years (32 years of median age) that participated in the '2017 Malawi STEPwise Approach to Non-

Communicable Disease Risk-Factor Surveillance survey.'

Primary and secondary outcome measures Selfreported history of IHD and/or stroke, along with biological, behavioural, psychosocial stress and sociodemographic covariates. Multivariable logistic regression calculated $\mathrm{OR}$ with $95 \% \mathrm{CI}$ for IHD and/or stroke.

Results The prevalence of IHD and/or stroke was $6.5 \%, 4.4 \%$ among men and $8.4 \%$ among women. In adjusted logistic regression analysis, older age (50-69 years) (adjusted OR (AOR) 3.49, 95\% Cl 1.75 to 6.94 ), female sex (AOR 2.09, 95\% Cl 1.45 to 3.01), Chewa speaking (AOR 4.62, 95\% $\mathrm{Cl} 1.32$ to 16.22), English speaking (AOR 5.63, 95\% Cl 1.43 to 22.19), suicidal ideation, plan and/or attempt (AOR 1.87, 95\% CI 1.11 to 3.13) and sedentary behaviour (AOR 2.00, $95 \% \mathrm{Cl} 1.12$ to 3.59 ) were associated with IHD and/or stroke. In addition, in unadjusted analysis, non-paid or unemployed, urban residence, overweight, obesity and having hypertension were associated with IHD and/or stroke.

Conclusions Almost 1 in 10 women and 1 in 20 men aged 18-69 years had IHD and/or stroke in Malawi.

Several risk and protective factors were found that can be targeted in population health interventions.

\section{BACKGROUND}

It is 'estimated that 17.9 million people died from cardiovascular diseases (CVDs) in 2016, representing $31 \%$ of all global deaths. Of these deaths, $85 \%$ are due to heart attack and stroke,' and three quarters occur in low-income and middle-income countries. ${ }^{1}$ In older persons in 2019, 'ischaemic heart disease (IHD) and stroke
Strengths and limitations of this study

- The study used a large nationally representative community-based sample of 4187 adults in Malawi.

- A large number of covariates, including sociodemographic factors, psychosocial stress, biological and behavioural risk factors of ischaemic heart disease (IHD) and/or stroke were incorporated in the final adjusted logistic regression model.

- The study assessed IHD and/or stroke by self-report, which may bias the IHD and/or stroke prevalence.

- Length of IHD and/or stroke diagnosis and cardiovascular disease type were not assessed.

were the top-ranked causes of disability-adjusted life-years.' 'Heart attacks and strokes are usually acute events and are mainly caused by a blockage that prevents blood from flowing to the heart or brain.'

In studies in low-income and middle-income countries, in urban-rural sites (35-70 years) in South Africa, Tanzania and Zimbabwe, the proportion of self-reported CVD (SRCVD) was $4.7 \%, 5.1 \%$ and $5.7 \%$, respectively. ${ }^{3}$ In national studies, for example, in Brazil, 1.6\% $\left(\geq 18\right.$ years) had self-reported (SR) stroke, ${ }^{4}$ in Ghana, $2.8 \%$ and $13.1 \%$ ( $\geq 50$ years) had SR stroke and angina, respectively, ${ }^{5}$ in Nepal, 2\% (24-64 years) had IHD and/or stroke, ${ }^{6}$ in China, $3.3 \%$ and $3.6 \%$ (35-74 years), ${ }^{7}$ in Thailand, $1.5 \%$ and $1.7 \%$ (35-74 years) had SRCVD in men and women, respectively, ${ }^{7}$ and in Iran, 5.3\% (20-69 years) had self-reported coronary heart disease (CHD) ${ }^{8}$ We were unable to identify national studies on SRCVD in Malawi, a low-income country in Southern Africa. ${ }^{9}$ One in 10 persons (10\%) died from CVDs in 2016 in Malawi. ${ }^{10}$ It has been estimated that rheumatic heart disease (with a prevalence of 183200 cases) is a major public health problem in Malawi. ${ }^{9}$ In a hospital-based 
study in Northern Malawi, 'out of the 3908 new Malawian patients included in the 5-year period register, $34 \%$ had valvular heart disease (mainly rheumatic heart disease); $24 \%$, hypertensive heart disease; $19 \%$, cardiomyopathies and $14 \%$, pericardial diseases.' ${ }^{10}$

Factors that increase the risk of SRCVD include sociodemographic, behavioural and biological variables. Socio and demographic factors increasing the odds of SRCVD include advanced age, ${ }^{8} 11{ }^{12} \mathrm{sex},{ }^{811-13}$ lower socioeconomic status, ${ }^{41-14}$ urban residence ${ }^{8}$ and ethnic group. ${ }^{15}$ Behavioural variables increasing the odds of SRCVD include tobacco use, ${ }^{12}{ }^{16}$ low physical activity, ${ }^{47}$ poor diet (low fruit/vegetable intake, ${ }^{617}$ and salt consumption ${ }^{18}{ }^{19}$ ) and mental distress. ${ }^{20-22}$ Biological variables increased the odds of SRCVD include hypertension, ${ }^{8} 12$ 14-17 2324 diabetes, ${ }^{41214-1723}$ obesity ${ }^{414161723}$ and abnormal cholesterol values. ${ }^{813}$ This study aimed to determine the prevalence and correlates of IHD and/or stroke in a national community-based study among adults in Malawi in 2017.

\section{METHOD}

\section{Sample and procedure}

The study analysed data from persons that participated in the nationally representative cross-sectional '2017 Malawi STEPwise Approach to Non-Communicable Disease Risk-Factor Surveillance (STEPS) survey'. ${ }^{25}$ Using a multistage cluster sampling approach, the survey generated nationally representative community-based data for adults (18-69 years) in Malawi. ${ }^{25}$ Inclusion criteria were one adult household member aged 18-69 per household who was able to provide informed consent. ${ }^{25}$ More information on the study methods and the data can be publicly accessed. ${ }^{25}$

\section{Measures}

Outcome variable: History of IHD and/or stroke was sourced from the item, 'Have you ever had a heart attack or chest pain from heart disease (angina) or a stroke (cerebrovascular accident or incident)?' (Yes, No).$^{25}$

Social and demographic variables consisted of educational level, sex, age, employment and marital status, residence and language of interview. ${ }^{25}$

Psychosocial stress included past 12-month suicidal ideation, suicide plan and attempt, and history of a family member attempting suicide. 'Alcohol family problems' was measured with the question, 'During the past 12 months, have you had family problems or problems with your partner due to someone else's drinking?' (' $1=y$ es: $>$ monthly to $4=$ once or twice') ${ }^{25}$

Biological variables consisted of measured body mass index classified as ' $<18.5 \mathrm{~kg} / \mathrm{m}^{2}$ underweight, 18.5-24.4 $\mathrm{kg} / \mathrm{m}^{2}$ normal weight, $25-29.9 \mathrm{~kg} / \mathrm{m}^{2}$ overweight and $\geq 30$ $\mathrm{kg} / \mathrm{m}^{2}$ obesity. ${ }^{26}$ Hypertension/raised blood pressure (BP) was classified as 'systolic BP $\geq 140 \mathrm{~mm} \mathrm{Hg}$ and/ or diastolic $\mathrm{BP} \geq 90 \mathrm{~mm} \mathrm{Hg}$ or where the participant is currently on antihypertensive medication. ${ }^{27}$ Diabetes was classified as 'fasting plasma glucose levels $\geq 7.0 \mathrm{mmol} / \mathrm{L}$ $(126 \mathrm{mg} / \mathrm{dL})$; or using insulin or oral hypoglycaemic
Table 1 Sample and self-reported ischaemic heart disease (IHD) and/or stroke characteristics among adults in Malawi, 2017: sociodemographic factors and psychosocial stress

\begin{tabular}{|c|c|c|}
\hline & Sample & $\begin{array}{l}\text { Self-reported } \\
\text { IHD and/or } \\
\text { stroke }\end{array}$ \\
\hline Variable & $\mathrm{N}(\%)$ & $\mathrm{N}(\%)$ \\
\hline \multicolumn{3}{|l|}{ Sociodemographic factors } \\
\hline All & 4187 & $312(6.5)$ \\
\hline \multicolumn{3}{|l|}{ Age (years) } \\
\hline $18-29$ & $1371(45.5)$ & $71(4.5)$ \\
\hline $30-49$ & $1890(39.7)$ & $136(6.8)$ \\
\hline $50-69$ & $926(14.7)$ & $105(11.9)$ \\
\hline \multicolumn{3}{|l|}{ Sex } \\
\hline Male & $1485(35.5)$ & $69(4.4)$ \\
\hline Female & $2702(64.5)$ & $243(8.4)$ \\
\hline \multicolumn{3}{|l|}{ Education } \\
\hline Secondary or more & $1057(24.7)$ & $81(7.1)$ \\
\hline Standard 5-8 & $1227(34.0)$ & $89(6.6)$ \\
\hline Standard 1-4 & $1318(31.1)$ & $101(5.8)$ \\
\hline None & $581(10.0)$ & $40(6.6)$ \\
\hline \multicolumn{3}{|l|}{ Marital status } \\
\hline Never married & $418(14.4)$ & $29(4.7)$ \\
\hline Married/cohabiting & $2888(73.0)$ & $209(6.7)$ \\
\hline Separated/divorced/widowed & $866(12.6)$ & $74(7.6)$ \\
\hline \multicolumn{3}{|l|}{ Employment status } \\
\hline Non-paid or unemployed & $2329(56.2)$ & $193(7.6)$ \\
\hline Employed or student & $1756(43.8)$ & $116(5.3)$ \\
\hline \multicolumn{3}{|l|}{ Residence } \\
\hline Rural & $3343(89.1)$ & $236(6.1)$ \\
\hline Urban & $844(10.9)$ & $76(10.0)$ \\
\hline \multicolumn{3}{|l|}{ Language of interview } \\
\hline Tumbuka & $145(4.3)$ & 7 (2.3) \\
\hline Chewa & $3535(78.3)$ & $243(6.1)$ \\
\hline English & $506(17.5)$ & $62(9.3)$ \\
\hline \multicolumn{3}{|l|}{ Psychosocial stress } \\
\hline \multicolumn{3}{|l|}{ Alcohol family problem } \\
\hline No & $3893(91.7)$ & $287(6.5)$ \\
\hline Yes & $294(8.3)$ & $25(6.6)$ \\
\hline \multicolumn{3}{|l|}{ Family member attempted suicide } \\
\hline No & $3975(94.6)$ & $290(6.4)$ \\
\hline Yes & $172(5.4)$ & $18(8.7)$ \\
\hline \multicolumn{3}{|l|}{ Suicidal ideation/plan/attempt } \\
\hline No & $3797(92.1)$ & $264(6.0)$ \\
\hline Yes & $331(7.9)$ & $45(11.6)$ \\
\hline
\end{tabular}

drugs; or having a history of diagnosis of diabetes. ${ }^{28}$ Raised total cholesterol (TC) was defined as 'fasting $\mathrm{TC} \geq 5.0 \mathrm{mmol} / \mathrm{L}$ or currently on medication for raised cholesterol.'. ${ }^{28}$ 
Table 2 Sample and self-reported ischaemic heart disease (IHD) and/or stroke characteristics among adults in Malawi, 2017: biological and behavioural risk factors

\begin{tabular}{lcc}
\hline & Sample & $\begin{array}{l}\text { Self-reported } \\
\text { IHD and/or } \\
\text { stroke }\end{array}$ \\
\hline $\begin{array}{l}\text { Variable } \\
\text { Biological risk factors }\end{array}$ & $\mathrm{N}(\%)$ \\
\hline Body mass index & & \\
\hline Normal & $2756(73.0)$ & $176(5.8)$ \\
\hline Underweight & $277(8.5)$ & $23(6.0)$ \\
\hline Overweight & $655(13.5)$ & $67(9.4)$ \\
\hline Obesity & $319(5.0)$ & $39(12.1)$ \\
\hline Hypertension & $3450(83.9)$ & $229(6.1)$ \\
\hline No & $727(16.1)$ & $83(8.7)$ \\
\hline Yes & $3590(97.0)$ & $272(6.8)$ \\
\hline Diabetes status & $103(1.7)$ & $7(5.7)$ \\
\hline No & $73(1.3)$ & $5(2.7)$ \\
\hline Pre-diabetes & & \\
\hline Diabetes & $3393(91.8)$ & $245(6.7)$ \\
\hline Raised total cholesterol & $457(8.2)$ & $47(6.3)$ \\
\hline No & & \\
\hline Yes & & \\
\hline
\end{tabular}

Behavioural risk factors

\begin{tabular}{|lrr}
\hline Smoking & $3639(84.1)$ & $279(6.7)$ \\
\hline Never & $188(4.6)$ & $19(8.6)$ \\
\hline Past & $360(11.2)$ & $14(3.9)$ \\
\hline Current & & \\
\hline Passive smoking & $3487(79.3)$ & $243(6.2)$ \\
\hline No & $700(20.7)$ & $69(7.7)$ \\
\hline Yes & & \\
\hline Alcohol dependence & $4035(95.0)$ & $305(6.7)$ \\
\hline No & $152(5.0)$ & $7(2.8)$ \\
\hline Yes & & \\
\hline Sedentary behaviour & $3351(94.4)$ & $266(6.8)$ \\
\hline No & $233(5.6)$ & $31(11.3)$ \\
\hline Yes & & \\
\hline No active transportation & $3822(92.0)$ & $281(6.2)$ \\
\hline No & $365(8.0)$ & $31(10.1)$ \\
\hline Yes & & \\
\hline Salt intake & $3696(90.4)$ & $284(6.5)$ \\
\hline Never/rarely/sometimes & $3494(82.6)$ & $268(6.9)$ \\
\hline Often/always & $685(17.4)$ & $44(4.4)$ \\
\hline Fruit/vegetable intake/day & & \\
\hline 5 or more servings & & \\
\hline$<5$ servings & & \\
\hline
\end{tabular}

Behavioural variables consisted of tobacco use, exposure to past month secondary smoking, daily servings of fruit and vegetable intake, and sedentary behaviour $(\geq 7$ hours/day) and no active transportation (measured with the 'Global Physical Activity Questionnaire ${ }^{25}{ }^{29}$ ). Salt consumption was sourced from the question, 'Do you add salt to food at the table?', ${ }^{25}$ and dichotomised into ' $0=$ never, rarely or sometimes, and $1=$ often or always.' Alcohol dependence was defined as $\geq 4$ total scores (items 4-6) from the 'Alcohol Use Disorder Identification Test (AUDIT) ${ }^{30}$

\section{Patient and public involvement}

The research questions assessed used existing data taken from large representative survey, 'STEPS', which contained more health questions and health measures than those presented in this work. Participants were not involved in the design of the study, recruitment or conduct of the study. STEPS participants receive their results from their physical and biochemical measurements. The study did not enlist participant opinion during study design but did have a plan to provide results to participants on physical blood measurements.

\section{Data analysis}

Statistical analyses were conducted with 'STATA software V.14.0 (Stata),' by considering the complex study approach. Logistic regression was used to estimate associations between independent variables and IHD and/ or stroke (dependent variable). The adjusted logistic regression model included all variables that were significant at $\mathrm{p}<0.1$ in unadjusted analyses. Missing values were excluded, and $\mathrm{p}<0.05$ was considered significant.

\section{RESULTS}

\section{Sample and IHD and/or stroke prevalence characteristics}

In all, 4187 persons (18-69 years, median 32, IQR 18), and $35.6 \%$ were male. Further, sociodemographic and psychosocial stress information is shown in table 1 . In terms of biological variables, $18.5 \%$ of participants were overweight or obese, $16.1 \%$ had hypertension, $1.7 \%$ prediabetes, $1.3 \%$ diabetes and $8.2 \%$ raised TC. Regarding behavioural risk factors, $4.6 \%$ were past and $11.2 \%$ current smokers, $20.7 \%$ had past 1 month exposure to secondary smoke, $5.0 \%$ were dependent on alcohol, $17.4 \%$ had often or always salt with their meals, $90.4 \%$ consumed insufficient fruit/vegetables, $5.6 \%$ engaged in sedentary behaviour and $8.0 \%$ did not participate in active transportation. The prevalence of IHD and/or stroke was $6.5 \%, 8.4 \%$ among women and $4.4 \%$ among men (see tables 1 and 2).

Associations with self-reported IHD and/or stroke prevalence In adjusted logistic regression analysis, older age (50-69 years) (adjusted OR (AOR) 3.49, 95\% CI 1.75 to 6.94), female sex (AOR 2.09, 95\% CI 1.45 to 3.01), Chewa speaking (AOR 4.62, 95\% CI 1.32 to 16.22), English speaking (AOR $5.63,95 \%$ CI 1.43 to 22.19 ), suicidal ideation, plan and/ or attempt (AOR 1.87, 95\% CI 1.11 to 3.13) and sedentary behaviour (AOR 2.00, 95\% CI 1.12 to 3.59) were associated 
Table 3 Univariate and multivariable associations with self-reported ischaemic heart disease and/or stroke: sociodemographic factors and psychosocial stress

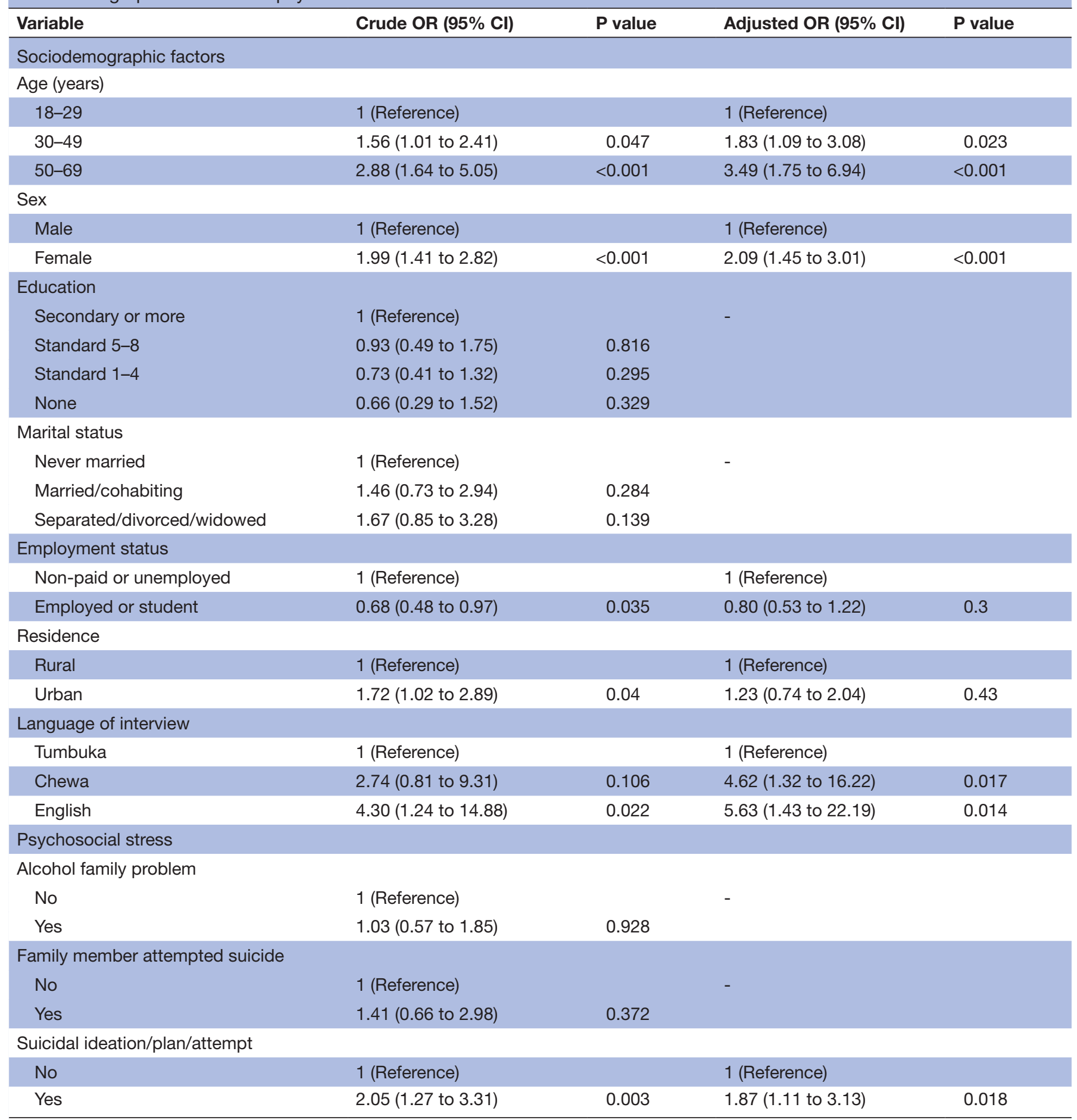

OR, Odds Ratio.

with IHD and/or stroke. In addition, in unadjusted analysis, non-paid or unemployed, urban residence, overweight, obesity and having hypertension were associated with IHD and/or stroke (see tables 3 and 4).

\section{DISCUSSION}

This is the first national study investigating the prevalence and correlates of IHD and/or stroke in Malawi. We found a high prevalence of IHD and/or stroke (6.5\%), and associated factors included older age, female sex, Chewa speaking, English speaking, suicidal ideation, plan and/or attempt and sedentary behaviour, and in unadjusted analysis, urban residence, overweight, obesity and having hypertension. The found prevalence of IHD and/or stroke in Malawi (6.5\%, 18-69 years) was higher than among 35-70 years in South Africa $(4.7 \%)$, Tanzania $(5.1 \%)$ and Zimbabwe $(5.7 \%),{ }^{3}$ 
Table 4 Univariate and multivariable associations with self-reported ischaemic heart disease and/or stroke: biological and behavioural risk factors

\begin{tabular}{|c|c|c|c|c|}
\hline Variable & Crude OR $(95 \% \mathrm{Cl})$ & $P$ value & Adjusted OR (95\% Cl) & $P$ value \\
\hline \multicolumn{5}{|l|}{ Biological risk factors } \\
\hline \multicolumn{5}{|l|}{ Body mass index } \\
\hline Normal & 1 (Reference) & & 1 (Reference) & \\
\hline Underweight & 1.04 (0.50 to 2.13$)$ & 0.923 & 1.03 (0.50 to 2.13$)$ & 0.938 \\
\hline Overweight & 1.67 (1.05 to 2.67$)$ & 0.032 & 1.20 (0.75 to 1.92$)$ & 0.451 \\
\hline Obesity & 2.23 (1.19 to 4.17$)$ & 0.012 & 1.40 (0.73 to 2.69$)$ & 0.309 \\
\hline \multicolumn{5}{|l|}{ Hypertension } \\
\hline No & 1 (Reference) & & 1 (Reference) & \\
\hline Yes & 1.47 (1.01 to 2.15$)$ & 0.044 & 1.04 (0.69 to 1.59$)$ & 0.839 \\
\hline \multicolumn{5}{|l|}{ Diabetes status } \\
\hline No & 1 (Reference) & & - & \\
\hline Pre-diabetes & 0.83 (0.31 to 2.26$)$ & 0.722 & & \\
\hline Diabetes & 0.38 (0.13 to 1.12$)$ & 0.079 & & \\
\hline \multicolumn{5}{|l|}{ Raised total cholesterol } \\
\hline No & 1 (Reference) & & - & \\
\hline Yes & 0.93 (0.51 to 1.70$)$ & 0.812 & & \\
\hline \multicolumn{5}{|l|}{ Behavioural risk factors } \\
\hline \multicolumn{5}{|l|}{ Smoking } \\
\hline Never & 1 (Reference) & & - & \\
\hline Past & 1.30 (0.61 to 2.75$)$ & 0.496 & & \\
\hline Current & $0.57(0.25$ to 1.31$)$ & 0.183 & & \\
\hline \multicolumn{5}{|l|}{ Passive smoking } \\
\hline No & 1 (Reference) & & - & \\
\hline Yes & $1.26(0.81$ to 1.96$)$ & 0.296 & & \\
\hline \multicolumn{5}{|l|}{ Alcohol dependence } \\
\hline No & 1 (Reference) & & - & \\
\hline Yes & 0.41 (0.14 to 1.20$)$ & 0.103 & & \\
\hline \multicolumn{5}{|l|}{ Sedentary behaviour } \\
\hline No & 1 (Reference) & & 1 (Reference) & \\
\hline Yes & 1.76 (0.99 to 3.13$)$ & 0.055 & 2.00 (1.12 to 3.59$)$ & 0.019 \\
\hline \multicolumn{5}{|l|}{ No active transportation } \\
\hline No & 1 (Reference) & & & \\
\hline Yes & 1.71 (0.67 to 4.34$)$ & 0.259 & - & \\
\hline \multicolumn{5}{|l|}{ Salt intake } \\
\hline Never/rarely/sometimes & 1 (Reference) & & & \\
\hline Often/always & 0.62 (0.34 to 1.12$)$ & 0.115 & - & \\
\hline \multicolumn{5}{|l|}{ Fruit/vegetable intake/day } \\
\hline 5 or more servings & 1 (Reference) & & & \\
\hline$<5$ servings & 1.08 (0.59 to 1.98$)$ & 0.765 & & \\
\hline
\end{tabular}

OR, Odds Ratio.

in Nepal (24-64 years; 2\%), ${ }^{6}$ in Brazil ( $\geq 18$ years; $1.6 \%$ SR stroke), ${ }^{4}$ in China $(35-74$ years; $<3.5 \%),{ }^{7}$ in Thailand $(35-74$ years; $1.5 \%$ in men and $1.7 \%$ in women $)^{7}$ and in Iran (20-69 years; $5.3 \% \mathrm{CHD}){ }^{8}$
In line with other studies, ${ }^{8} 1112$ advanced (45-69 years) increased the odds of IHD and/or stroke. In agreement with some studies, in particular in Africa, ${ }^{8}{ }^{13}$ the IHD and/or stroke prevalence was in this study significantly 
higher in women than in men. Compared with Tumbuka speaking participants, Chewa and English-speaking participants had a higher odd of IHD and/or stroke. This result may confirm that ethnicity contributes to higher IHD and/or stroke, as found in a study in Singapore. ${ }^{15}$ In line with previous research, ${ }^{8}$ this study found in unadjusted analysis that urban residence was associated with a higher prevalence of IHD and/or stroke. Some research showed that low socioeconomic status, ${ }^{13}{ }^{14}$ was associated with IHD and/or stroke, while in this study in unadjusted analysis non-paid or unemployed work status was associated with IHD and/or stroke. A few studies showed that lower education was associated with SRCVD, ${ }^{411} 12$ while we did not find significant differences in relation to educational level in this study.

Consistent with former studies, ${ }^{20-22}$ this survey found that suicidal behaviour (as a form of psychosocial stress) increased the odds of IHD and/or stroke. 'Stress can increase the cerebrovascular disease risk by modulating symphaticomimetic activity, affecting the BP reactivity, cerebral endothelium, coagulation or heart rhythm. . ${ }^{22}$ Consistent with previous research, ${ }^{4}{ }^{17}$ this study showed that sedentary behaviour increased the odds of IHD and/or stroke. Contrary to expectation, ${ }^{4} 6$ 16-19 smoking, frequent salt and insufficient fruit/vegetable intake were not significantly associated with IHD and/or stroke in this survey.

In line with previous research,, $81214-172324$ this survey found in unadjusted analyses associations between overweight/obesity, hypertension and IHD and/or stroke. Unlike some studies, ${ }^{4} 812$ 14-17 23 this survey did not show associations between raised TC, pre-diabetes, diabetes and IHD and/or stroke. It is possible that because of the low prevalence of prediabetes and diabetes $(<2 \%)$ no significant association with IHD and/or stroke was found.

The high prevalence of IHD and/or stroke found in Malawi emphasises the need for large community-based education operations, strengthening local health systems and providing Developmental Assistance for Health. ${ }^{13} 1631$ Considering that suicidal behaviour (as a form of psychosocial stress) was associated with IHD and/or stroke in this study, CVD screening and management may want to include screening for psychosocial stress. Primary prevention should be the main approach to reduce CVDs in Malawi, ${ }^{32}$ including as found in this study reducing sedentary behaviour, hypertension and preventing overweight/ obesity and psychological distress. ${ }^{20-22}$ Although Malawi has 'evidence-based national guidelines/protocols/standards for the management of major non-communicable diseases (NCDs) through a primary care approach,' there is a lack of an 'operational policy, strategy or action plan to reduce unhealthy diet and/or promote healthy diets and to reduce physical inactivity and/or promote physical activity'. ${ }^{1533}$ In addition to 'facility-based NCD screening and clinical services, active screening, prevention and community awareness and outreach' should be added. ${ }^{34}$

The study strengths include the use of a large nationally representative sample, information related to several confounders, and uniform STEPS measures and methods. Study limitations consist of the STEPS survey only being cross-sectional, which hinders us to draw causative conclusions. Furthermore, some variables, including IHD and/ or stroke, were assessed by self-report. However, SRCVD has been found 'valid for epidemiological studies'. ${ }^{35}$ Our estimates of IHD and/or stroke are likely to be an underestimate since the study excluded those with IHD and/or stroke who had died prior to the survey ${ }^{36}$ Future studies could measure the length of IHD and/or stroke and the CVD type.

\section{CONCLUSION}

Almost 1 in 10 women and 1 in 20 men aged 18-69 years had IHD and/or stroke in Malawi. Several associated factors for IHD and/or stroke, such as older age, female sex, Chewa or English speaking, suicidal ideation, plan and/or attempt and sedentary behaviour, were found that can be targeted in population health interventions.

Acknowledgements The data source, the World Health Organisation NCD Microdata Repository (URL: https://extranet.who.int/ncdsmicrodata/index.php/ catalog), is hereby acknowledged.

Contributors All authors fulfil the criteria for authorship. SP and KP conceived and designed the research, performed statistical analysis, drafted the manuscript and made critical revision of the manuscript for key intellectual content. All authors read and approved the final version of the manuscript and have agreed to authorship and order of authorship for this manuscript.

Funding The authors have not declared a specific grant for this research from any funding agency in the public, commercial or not-for-profit sectors.

Competing interests None declared.

Patient and public involvement Patients and/or the public were not involved in the design, or conduct, or reporting, or dissemination plans of this research.

Patient consent for publication Not applicable.

Ethics approval The Malawi National Health Sciences Research and Ethics Committee approved the study (no approval number) and participants provided written informed consent.

Provenance and peer review Not commissioned; externally peer reviewed.

Data availability statement Data are available in a public, open access repository. The data source is publicly available at the WHO NCD Microdata Repository (URL: https://extranet.who.int/ncdsmicrodata/index.php/catalog).

Open access This is an open access article distributed in accordance with the Creative Commons Attribution Non Commercial (CC BY-NC 4.0) license, which permits others to distribute, remix, adapt, build upon this work non-commercially, and license their derivative works on different terms, provided the original work is properly cited, appropriate credit is given, any changes made indicated, and the use is non-commercial. See: http://creativecommons.org/licenses/by-nc/4.0/.

ORCID iD

Karl Peltzer http://orcid.org/0000-0002-5980-0876

\section{REFERENCES}

1 World Health Organization (WHO). Cardiovascular diseases (CVDs), 2017. Available: https://www.who.int/news-room/fact-sheets/detail/ cardiovascular-diseases-(cvds)

2 GBD 2019 Diseases and Injuries Collaborators. Global burden of 369 diseases and injuries in 204 countries and territories, 1990-2019: a systematic analysis for the global burden of disease study 2019 . Lancet 2020;396:1204-22.

3 Murphy A, Palafox B, O'Donnell O, et al. Inequalities in the use of secondary prevention of cardiovascular disease by socioeconomic 
status: evidence from the PURE observational study. Lancet Glob Health 2018;6:e292-301.

4 Ribeiro Ícaro J S, Cardoso JP, Freire IV, et al. Determinants of stroke in Brazil: a cross-sectional multivariate approach from the National health survey. J Stroke Cerebrovasc Dis 2018;27:1616-23.

5 Ruan Y, Guo Y, Zheng Y, et al. Cardiovascular disease (CVD) and associated risk factors among older adults in six low-and middleincome countries: results from sage wave 1. BMC Public Health 2018;18:778.

6 Nepali S, Rijal A, Olsen MH, et al. Factors affecting the fruit and vegetable intake in Nepal and its association with history of selfreported major cardiovascular events. BMC Cardiovasc Disord 2020;20:425

$7 \mathrm{He} \mathrm{J}$, Neal B, Gu D, et al. International collaborative study of cardiovascular disease in Asia: design, rationale, and preliminary results. Ethn Dis 2004;14:260-8.

8 Abbasi M, Neishaboury M, Koohpayehzadeh J, et al. National prevalence of self-reported coronary heart disease and chronic stable angina pectoris: factor analysis of the underlying cardiometabolic risk factors in the SuRFNCD-2011. Glob Heart 2018;13:73-82.

9 Sanyahumbi A, Chiromo P, Chiume M. Education: the prevention of acute rheumatic fever and rheumatic heart disease in Malawi. Malawi Med J 2019;31:221-2.

10 Soliman EZ, Juma H. Cardiac disease patterns in northern Malawi: epidemiologic transition perspective. J Epidemiol 2008;18:204-8.

11 Abdalla SM, Yu S, Galea S. Trends in cardiovascular disease prevalence by income level in the United States. JAMA Netw Open 2020;3:e2018150.

12 Gikas A, Lambadiari V, Sotiropoulos A, et al. Prevalence of major cardiovascular risk factors and coronary heart disease in a sample of Greek adults: the Saronikos study. Open Cardiovasc Med J 2016;10:69-80.

13 Keates AK, Mocumbi AO, Ntsekhe M, et al. Cardiovascular disease in Africa: epidemiological profile and challenges. Nat Rev Cardiol 2017;14:273-93.

14 Ghaemian A, Nabati M, Saeedi M, et al. Prevalence of self-reported coronary heart disease and its associated risk factors in Tabari cohort population. BMC Cardiovasc Disord 2020;20:238.

15 World Health Organization. Noncommunicable diseases (Ncd) country profiles, Malawi, 2018. Available: https://www.who.int/nmh/ countries/mwi en.pdf?ua=1 [Accessed 10 Nov 2020].

16 Hennis A, Hambleton I, Fraser $\mathrm{H}$, et al. Risk factors for cardiovascular disease in the elderly in Latin America and the Caribbean. Prevention and Control 2006;2:175-85.

17 Fuchs SC, Moreira LB, Camey SA, et al. Clustering of risk factors for cardiovascular disease among women in Southern Brazil: a population-based study. Cad Saude Publica 2008;24:s285-93.

18 Poggio R, Gutierrez L, Matta MG, et al. Daily sodium consumption and CVD mortality in the general population: systematic review and meta-analysis of prospective studies. Public Health Nutr 2015;18:695-704.
19 Mozaffarian D, Fahimi S, Singh GM, et al. Global sodium consumption and death from cardiovascular causes. N Engl J Med 2014;371:624-34.

20 Atlantis E, Sullivan T. Changes in cardiovascular disease burden associated with psychopathology in Australian adults 2004-2008. Gen Hosp Psychiatry 2012;34:345-51.

21 O'Donnell MJ, Xavier D, Liu L, et al. Risk factors for ischaemic and intracerebral haemorrhagic stroke in 22 countries (the INTERSTROKE study): a case-control study. Lancet 2010;376:112-23.

22 Kotlega D, Gołąb-Janowska M, Masztalewicz M, et al. The emotional stress and risk of ischemic stroke. Neurol Neurochir Pol 2016;50:265-70.

23 Aniza I, Nurmawati A, Hanizah Y, et al. Modifiable risk factors of cardiovascular disease among adults in rural community of Malaysia: a cross sectional study. MJPHM 2016;16:53-61.

24 Wasay M, Khatri IA, Kaul S. Stroke in South Asian countries. Nat Rev Neurol 2014;10:135-43.

25 World Health Organization (WHO). NCD Microdata Repository. Malawi - STEPS 2017, 2020. Available: https://extranet.who.int/ ncdsmicrodata/index.php/catalog/629 [Accessed 10 Nov 2020].

26 World Health Organization (WHO), Europe. Body mass index. Available: https://www.euro.who.int/en/health-topics/diseaseprevention/nutrition/a-healthy-lifestyle/body-mass-index-bmi [Accessed 20 Sep 2020].

27 Chobanian AV, Bakris GL, Black HR, et al. Seventh report of the joint National Committee on prevention, detection, evaluation, and treatment of high blood pressure. Hypertension 2003;42:1206-52.

28 World Health Organization (WHO). WHO steps surveillance manual. Available: https://www.who.int/ncds/surveillance/steps/STEPS Manual.pdf [Accessed 10 Oct 2020].

29 Armstrong T, Bull F. Development of the World Health organization global physical activity questionnaire (GPAQ). J Public Health 2006;14:66-70.

30 Australian Government. Alcohol screen (audit). Available: http:// nceta.flinders.edu.au/files/3314/2257/4957/Right_Mix_3.pdf [Accessed 10 Nov 2020].

31 Kalkonde YV, Alladi S, Kaul S, et al. Stroke prevention strategies in the developing world. Stroke 2018;49:3092-7.

32 Yuyun MF, Sliwa K, Kengne AP, et al. Cardiovascular diseases in sub-Saharan Africa compared to high-income countries: an epidemiological perspective. Glob Heart 2020;15:15

33 Juma PA, Mohamed SF, Matanje Mwagomba BL, et al. Noncommunicable disease prevention policy process in five African countries. BMC Public Health 2018;18:961.

34 Lupafya PC, Mwagomba BLM, Hosig K, et al. Implementation of policies and strategies for control of noncommunicable diseases in Malawi: challenges and opportunities. Health Educ Behav 2016;43:64S-9.

35 Jamrozik E, Hyde Z, Alfonso $\mathrm{H}$, et al. Validity of self-reported versus hospital-coded diagnosis of stroke: a cross-sectional and longitudinal study. Cerebrovasc Dis 2014;37:256-62.

36 Zaw KK, Nwe N, Hlaing SS. Prevalence of cardiovascular morbidities in Myanmar. BMC Res Notes 2017;10:99. 